\title{
A evolução da agroindústria de laticínios no Brasil com base nos indicadores de estrutura, conduta e desempenho
}

\author{
Evandro Sadi Vargas* \\ Joel Fiegenbaum**
}

\section{Resumo}

O presente artigo analisa as mudanças estruturais da indústria de laticínios no Brasil e nos estados do RS, SC e MG no período de 1996 a 2010. Tem como método o modelo de estrutura da conduta e desempenho (ECD) para verificar a evolução da estrutura por meio do cálculo da razão de concentração e de indicadores técnico-econômicos, bem como as estratégias de Porter para a análise da conduta e do desempenho da agroindústria de laticínios. Os resultados mostram uma estrutura de oligopólio pouco concentrada com margens de custos de produção estáveis. Quanto à evolução da conduta pode-se dizer que houve diversificação da produção e diferenciação dos produtos. A análise do desempenho demonstrou que houve uma melhoria na eficiência produtiva tanto para o Brasil, quanto para os estados pesquisados, demonstrada pelo aumento da produtividade do trabalho. $\mathrm{O}$ estado de SC teve aumento do desempenho na produtividade do trabalho e na retenção de lucros. Os estados do RS e de MG apresentaram maior eficiência produtiva nos demais indicadores, refletindo em um desempenho superior em relação à SC.

Palavras-chave: Evolução estrutural. Desempenho de indicadores técnicos e econômicos.

* Mestrando pela Universidade Federal de Santa Maria (UFSM) no Programa de Pós-Graduação em Economia e Desenvolvimento. E-mail: evandro_vargas@yahoo.com.br.

** Mestre em Economia pela Universidade Federal de Santa Maria (UFSM) - Programa de Pós-Graduação em Economia e Desenvolvimento. E-mail: jfigo2002br@yahoo.com.br.

http://dx.doi.org/10.5335/rtee.v20i42.4475

Submissão: 29/11/2013. Aceite: 26/06/2014 


\section{Introdução}

Na década de 1990, houve um processo de desregulamentação do mercado nacional e da abertura do comércio, o que ocasionou na reestruturação de todo $o$ sistema agroindustrial no setor leiteiro, desde a produção da matéria-prima (leite) na agroindústria de láctea até a distribuição do produto no mercado. Houve a entrada de empresas multinacionais no país, via fusões e aquisições, alterando o nível de competitividade e trazendo novos desafios para as empresas nacionais, principalmente de pequeno e médio porte. Além disso, a abertura comercial permitiu a importação de produtos lácteos principalmente do Mercosul e da União Europeia, com preço e qualidade mais competitivos. A maior importação, também, ocorreu em função da estabilização econômica do país, a partir de 1994, pelos ganhos de renda real da população e pela valorização cambial. ${ }^{1}$ A partir de 1999, com a liberalização cambial, houve a desvalorização da moeda nacional, que, refletida nos preços, gerou impacto positivo, aumentando a competitividade da produção brasileira de lácteos.

A partir da primeira década do Século XXI, após passar por um período de incertezas em função da troca de governo, a economia brasileira demonstrou-se capaz de honrar seus compromissos perante a economia internacional, adotando como compromisso com os credores da divida do país, o superávit primário e as metas de inflação para garantir a estabilidade de preços da economia. Conforme Homen de Melo (1999), a agroindústria, no geral, também sofreu grandes impactos em função não apenas das políticas liberalizantes, mas, também, pela forma como essas políticas foram adotadas, principalmente a partir dos anos 1990.

O agronegócio do leite teve que se ajustar à nova realidade econômica mundial. A rápida transformação impactou a concorrência e o setor estava despreparado, causando, inicialmente, vários desajustes em toda sua extensão, tanto a jusante quanto a montante do setor lácteo.

Este trabalho torna-se relevante pela importância para a economia brasileira, na geração de emprego e renda, pois, o Brasil classifica-se entre os principais países produtores de leite e derivados, com as maiores empresas atuantes internamente, as quais são tanto multinacionais, como nacionais e cooperativas. Com base no contexto de mudanças gerais da política econômica brasileira dos anos de 1990, e após o país obter confiança dos agentes em sua política de estabilização, objetivou-se analisar como evoluiu a estrutura, a conduta e o desempenho dos laticínios por meio de indicadores técnicos e econômicos. Para tanto, utilizou-se a razão de concentração, as margens de custos e estratégias de Porter, indicadores 
de produtividade e de rentabilidade da agroindústria brasileira no período de 1996 a 2010 , respectivamente.

A pesquisa abrange a agroindústria láctea brasileira para o cálculo de concentração e, para os demais indicadores, a média nacional, os estados de Santa Catarina, Rio Grande do Sul e Minas Gerais.

$\mathrm{O}$ artigo encontra-se estruturado em cinco seções, além dessa introdução. A segunda seção aborda aspectos gerais das transformações da economia brasileira, bem como dos laticínios na década de 1990 e na primeira década do Século XXI. A terceira apresenta o referencial teórico utilizado. A quarta seção trata dos aspectos metodológicos da pesquisa. A quinta seção apresenta e discute os resultados. A última seção sintetiza as principais conclusões do estudo realizado.

\section{Revisão bibliográfica}

A indústria de alimentos foi destaque na recepção de investimentos estrangeiros e diretos, no período de 1996 a 2000 (MAZZETTO et al., 2007). Conforme Carvalho (2002) ocorreram, nas últimas décadas, várias transformações no setor produtivo de leite: primeiro em função da abertura comercial, que propiciou um fluxo intenso de capitais externos responsáveis pelas fusões e aquisições; segundo, pela desregulamentação do mercado, ocasionando o fim do controle e o tabelamento dos preços do leite, incentivando, com isso, a entrada de novas empresas (multinacionais), visto que possibilitou o aumento da margem de lucro na fabricação de novos produtos. Consequentemente, o governo deixou de ser o demandante do setor interno, bem como o importador de lácteos, viabilizando a entrada do setor privado nesse campo de atuação.

Conforme ressalta Melo (2002), a partir da década de 1990, as cooperativas tiveram que alterar o padrão de concorrência da indústria no Brasil, a fim de sobreviver no mercado de laticínios. Essa nova estratégia teve como característica principal a redução de custo e a modernização de processos produtivos e de reorientação de negócios. Conforme Martins (2004), no setor industrial, houve um processo de concentração, com aquisição de laticínios médios por grandes empresas. Esse processo foi provocado, principalmente, por empresas de capital transnacional, que aumentaram sua participação no mercado brasileiro.

A indústria nacional e principalmente as cooperativas sofreram com a concorrência de produtos importados, causando a queda dos preços internos, assim como, também, a disseminação do consumo de leite Longa Vida. O surgimento desse produto foi uma estratégia competitiva da Parmalat que buscava alterar os hábitos 
alimentares. Além disso, o maior prazo de validade permitiu ao comércio de leite fluido expandir-se além das fronteiras regionais (MELO, 2002, p. 2).

Ainda, segundo o mesmo autor:

A reestruturação industrial do setor de laticínios no Brasil dá-se durante a década de 90 e decorre da reestruturação europeia e americana, tendo sido liderada pela expansão das empresas multinacionais em busca de mercados adicionais para a valorização de seus ativos (2002, p. 3).

Essas empresas, fixadas no mercado brasileiro pelas fusões e aquisições, buscavam estratégias como a redução dos custos, afastando produtores ineficientes e diferenciando seus produtos pela inovação. Segundo Pochmann (2001), quanto à conduta empresarial, a partir de 1990, as empresas tiveram de se adaptar ao novo cenário de estabilidade monetária, de abertura comercial, de câmbio valorizado, até fins dos anos 1990. As grandes empresas investiram em tecnologias e a maioria do setor empresarial difundiu o uso de programa de gestão na produção e na reorganização do trabalho. Essas medidas resultaram no enxugamento de postos de trabalho.

De acordo com Dunning (1998 apud MELO, 2002), uma das vantagens para a empresa capitalista tornar-se apta internacionalmente é a vantagem locacional, a qual faz de um lugar determinado, um espaço de produção mais favorável que outro. Essas condições relacionam-se com o tamanho do mercado, com suas condições de demanda, com custos locais relativos à produção e com condições políticas e culturais (MELO, 2002).

Segundo Jank e Galan (1998, p. 183):

O sistema agroindustrial do leite se alterou muito nos últimos anos, em função das novas variáveis da política pública (desregulamentação, abertura comercial, integração, estabilização) e seus reflexos no ambiente competitivo (concentração e internacionalização da indústria, novas embalagens, maior poder dos supermercados, pagamento diferenciado, etc.).

Os autores argumentam que a criação do leite pasteurizado fez aproximar produtores de grandes varejistas e isso levou ao desequilíbrio das bacias leiteiras tradicionais que abasteciam os mercados locais. A partir dos anos 1990, a indústria leiteira brasileira estimulou o aumento da produção de seus fornecedores que passaram a adotar políticas de estímulo ao transporte a granel com diferenciação dos preços para reduzir custos operacionais (MARTINS; GOMES, 2000).

Houve ainda, no setor industrial, um processo de concentração, com aquisição de laticínios médios por grandes empresas (BARROS et. al. 2001; INSTITUTO GLOBAL MACKNSEY, 1999; MARTINS; YAMAGUCHI, 1998 apud MARTINS 
2004). Esse processo foi alavancado principalmente pelas empresas de capital transnacional, que aumentaram a sua participação no mercado brasileiro (DE NEGRI, 1997 apud MARTINS, 2004). Segundo Martins (2004, p. 21), após a desregulamentação do mercado de laticínios, houve uma intensa turbulência, "motivada por interesses diferenciados de produtores e indústria". Verificou-se, ainda, um esforço para reduzir custos, aumentar a eficiência, melhorar a qualidade e diversificar os derivados ofertados.

Conforme Martins e Gomes (2000), a década de 1980, foi caracterizada pelo controle de preços e pela recessão econômica, inibindo a retenção de produtos comerciais dispostos a investir em tecnologia e desestimulando o crescimento na demanda de laticínios. Enquanto que, na indústria, houve a incorporação de laticínios de administração familiar, por grupos maiores, notadamente multinacionais.

Quando o tabelamento terminou, o produtor não sabia produzir, a indústria não sabia fabricar e o consumidor não tinha o que escolher. As principais medidas, do Primeiro Plano Collor, tinham por objetivo baixar a inflação e reduzir o déficit público. Como consequência, as indústrias de laticínios foram vendidas ou fechadas. Das nove cooperativas centrais de laticínios existentes em 1980, sobraram duas. As pequenas indústrias sobrevivem, mas fora do âmbito dos grandes centros, e os grandes e médios laticínios nacionais associaram-se ou oram vendidos. A criação de blocos econômicos, como o Mercosul, favoreceu a competição entre produtos de diferentes países, levando o consumidor a ocupar um patamar mais elevado, pois, aprendeu a escolher e a reclamar (PRIMO, 2000).

Segundo o mesmo autor (2000), o que contribuiu para impulsionar a eficiência do setor, nos anos 1990, foi a entrada do leite Longa Vida, pela sua facilidade de distribuição, pela redução de custos na distribuição e pelo aumento de sua vida útil. Além disso, o fato de ser um produto de fácil transporte no que diz respeito ao tempo e ao espaço, ou seja, pode ser produzido na safra e distribuído na entressafra, em decorrência do deslocamento da produção, em que bacias leiteiras tradicionais perto dos centros consumidores puderam se deslocar para outras regiões a fim de baratear a produção. Outro importante fator foi a aceitação do consumidor.

O Leite Longa Vida impulsionou todo o setor para melhoria da qualidade da matéria-prima, pois, ao iniciar o processo de ultrapasteurização, o rendimento das máquinas ficou abaixo do esperado, isso, em função da baixa qualidade do leite (PRIMO, 2000). 


\section{Referencial teórico}

A agroindústria tem como principal matéria-prima um produto da agropecuária, por exemplo, um conjunto de laticínios (Bacha, 2004). Esses são responsáveis pela aquisição, pelo processamento e pela produção dos derivados do leite e integram o sistema agroindustrial de laticínios, que é formado pelos fornecedores de insumos, máquinas, equipamentos, pecuária leiteira, processamento e distribuição. O processamento, atividade da indústria de laticínios, é realizado por empresas multinacionais, grupos nacionais, cooperativas e pequenos laticínios Jank (1999 apud CARVALHO, 2002).

Conforme Zylbertsztajn e Neves (2000), o estudo de sistemas agroindustriais tem ampla aplicação desde os trabalhos realizados por Davis e Goldberg (1957) e Goldberg (1968). Esses autores constataram que as indústrias de insumos, a produção agropecuária, a indústria de alimentos e o sistema de distribuição mantêm relações de dependência.

A importância da indústria se deve, em grande parte, ao fato de que, quando utilizam tecnologias intensivas em trabalho, geram emprego para um grande contingente de mão-de-obra, especialmente a sem grande qualificação, contribuindo, dessa maneira, para um aumento do bem-estar da sociedade (BRUMER, 1981, p. 7).

Para estudar a evolução e as principais tendências da indústria de laticínios, será utilizado o modelo ECD. A escolha baseia-se no fato de esse ser um modelo que proporciona vasto entendimento e grande quantidade de informações a respeito de uma indústria. E, a fim de analisar o desempenho e competitividade, optou-se por utilizar os indicadores técnicos e econômicos dessa indústria baseados em Possas (1977) e Melo (2002).

Segundo Marion Filho (1997), a concepção do modelo ECD é atribuída a Edward S. Mason (1939) e a seus colegas de Harvard, mas foi com Joe Bain, na década de 1950, que se iniciou a formalização teórica do paradigma ECD. Conforme Schmalensee (1992, p. 952 apud MARION FILHO, 1997), "nos primeiros trabalhos de Bain, as pesquisas empíricas sobre a organização da indústria envolviam estudos de caso detalhados de indústrias selecionadas". Na versão tradicional de Mason (1939) e Bain (1968 apud SANTOS; SANTANA, 2003), "o modelo postula relações causais unidirecionais entre a estrutura de mercado, a conduta das empresas e o desempenho econômico".

O modelo tradicional possui suas críticas. Uma, refere-se ao fato de incorporar hipóteses do modelo neoclássico particularmente ao adotar o equilíbrio de mercado e a informação simétrica. 
Ferguson e Ferguson (1999 apud SANTOS; SANTANA, 2003) sustentam que:

As relações entre estrutura, conduta e desempenho são mais complexas do que a originalmente exposta no modelo tradicional. Sendo assim, a análise da conduta, em alguns casos, é tida como secundária, visto que o desempenho pode ser identificado diretamente a partir da estrutura de mercado, pois consideram que estas oferecem informações suficientes para deduzir como empresas têm que se comportar.

Outra refere-se à crítica que o modelo recebeu sobre a premissa de que, a estrutura de mercado é determinada exogenamente, pois, atribui um caráter estático ao modelo, deixando de incorporar o processo de inovação tecnológica e as estratégias empresariais como fatores determinantes da organização dos mercados. Para um ambiente econômico atual, fez-se necessário integrar novos elementos ao modelo. Farina et al. (1997 apud SANTOS; SANTANA, 2003) destacam que, a partir da década de 1980, os estudos de organização industrial procuraram considerar as estruturas de mercado como determinadas endogenamente. Ferguson e Ferguson (1994) e Carlton e Perloff (1999) incorporaram ao modelo tradicional fluxos bidirecionais entre os ambientes da estrutura, conduta e desempenho, pois, admitem que a conduta das empresas e o seu desempenho são simultaneamente determinados, bem como podem influenciar sua estrutura.

No presente estudo, foi adotado o modelo apresentado por Carlton e Perloff (1990, p. 4 apud MARION FILHO, 1997, p. 35) que descreve as variáveis da estrutura, conduta e desempenho, as condições básicas da oferta e da demanda, como também as políticas governamentais (Figura 1).

Segundo Aguiaf (1994), a estrutura é a forma de organização do mercado, a conduta consiste nas estratégias seguidas por vendedores e compradores e o desempenho é o grau de atendimento da sociedade pelo mercado. Esse modelo demonstra que, além de a estrutura, a conduta e o desempenho serem afetados pelas condições básicas de oferta e demanda, as políticas públicas também influenciam nas mudanças. Segundo Kupfer (2002, p. 109), “indústrias com grau elevado de concentração seriam as mais lucrativas. Inversamente, estruturas industriais mais atomizadas seriam as menos lucrativas". Entretanto, de acordo com o mesmo autor, alguns estudos empíricos revelam que a hipótese de que a lucratividade de uma indústria é positivamente correlacionada ao grau de concentração levou a resultados poucos conclusivos. 
Figura 1 - Modelo das relações entre estrutura, conduta e desempenho



Fonte: adaptada de Carlton e Perloff (1990, p. 4 apud MARION FILHO, 1997, p. 35). 
A fim de completar a análise, optou-se por utilizar indicadores técnicos e econômicos para a agroindústria de lácteos que permitem verificar o desempenho por meio da eficiência produtiva, do progresso técnico e da rentabilidade. Os indicadores utilizados são as margens sobre os custos, índices de produtividade e rentabilidade que são especificados na metodologia. No presente estudo, serão utilizadas as estratégias competitivas de Porter (2004), como base para definição das condutas adotadas pelas empresas na indústria de laticínios. Em seu trabalho, Porter (2004) aborda três estratégias competitivas genéricas: liderança no custo total, diferenciação e enfoque.

$\mathrm{Na}$ estratégia de liderança de custos, existe a busca pela minimização dos custos em relação aos concorrentes, não deixando de levar em conta aspectos relacionados à qualidade, à assistência técnica necessária, entre outras áreas. Tal estratégia consiste na construção agressiva de instalações em escala eficiente, uma drástica redução de custos pela experiência, em consonância com um controle rígido dos custos e das despesas gerais, a não formação de contas marginais dos clientes, além da diminuição dos custos em áreas de $\mathrm{P} \& \mathrm{D}$, assistência, força de vendas, publicidade, etc. Assim, a empresa cria uma defesa contra a rivalidade dos concorrentes, pois os custos mais baixos permitem que ela ainda obtenha retornos depois que os concorrentes tenham consumido seus lucros na competição.

$\mathrm{Na}$ estratégia da diferenciação, busca-se criar algo que seja considerado único em toda a indústria. Os métodos para essa diferenciação, conforme Porter (2004) abrangem projetos ou imagem da marca, tecnologia, peculiaridades, serviços sobencomenda, rede de fornecedores, entre outras dimensões. Busca-se, por meio da diferenciação, obter retornos acima da média em uma indústria, além do fato de que ela proporciona um isolamento contra a rivalidade competitiva devido à lealdade do consumidor à determinada marca e a, consequente, menor sensibilidade ao preço. Ainda, segundo o autor, é ressaltado que esta estratégia não ignora os custos, mas esses não são o alvo estratégico primário.

$\mathrm{Na}$ estratégia de enfoque, as empresas buscam determinado grupo de compradores, um segmento da linha de produtos, ou um mercado geográfico. Diferentemente das estratégias de liderança de custos e diferenciação, o enfoque busca atingir muito bem a um alvo determinado. Assim, busca-se atender o alvo de forma efetiva ou eficiente, diferente dos concorrentes que atuam de forma mais ampla na indústria. Segundo Porter (2004), por meio da estratégia do enfoque, a empresa acaba, consequentemente, por atingir a diferenciação tendo em vista que satisfaz melhor as necessidades de seus alvos, ou devido à redução de custos na obtenção desses alvos, ou ainda uma mescla dos dois aspectos citados anteriormente. 


\section{Metodologia}

\subsection{Método de abordagem}

Foi utilizado o método descritivo da agroindústria de laticínios, que permitiu analisar a evolução da agroindústria no contexto econômico ao mensurar os indicadores de estrutura e de desempenho.

\subsection{Método de procedimento}

O método de procedimento da pesquisa ocorreu por meio de coleta, sistematização e análise dos dados e informações (secundárias) que possibilitaram a caracterização da indústria de laticínios. As fontes consultadas foram publicações especializadas da indústria - dados de associações e instituições setoriais como a Leite Brasil e a Empresa Brasileira de Pesquisa Agropecuária (Embrapa), além de dados de órgãos públicos, tais como da Fundação de Economia e Estatística (FEE) e do Instituto Brasileiro de Geografia e Estatística (IBGE).

Para os cálculos dos indicadores, foram utilizados dados da Embrapa Gado de Leite e dados da Pesquisa Industrial Anual (PIA) do IBGE, utilizando-se da classificação 15.4, no período de 1996 a 2003, e 10.5, no período de 2004 a 2010 (fabricação de produtos de laticínios) do Código Nacional de Atividades Econômicas (CNAE) do IBGE para o período de 1996 a 2010. Destaca-se que, para o Brasil, são utilizados dados consolidados das empresas com cinco ou mais pessoas ocupadas e, para a análise dos estados apresentados nesse trabalho, serão utilizados os dados de unidades produtivas com mais de cinco pessoas empregadas.

A seguir, são feitas descrições da forma de cálculo e uma discussão sucinta do significado dos indicadores técnicos e econômicos da indústria que foram analisados no trabalho. Esse procedimento foi baseado em Possas (1977), Tavares et al. (1978) e Lannes (2002) para os indicadores de desempenho e Resende e Boff (2002) para a razão de concentração.

\subsubsection{Estrutura - Indicador de concentração}

Um indicador de concentração pretende fornecer uma medida de concorrência existente em um mercado. Para identificar a estrutura da indústria de laticínios, foi utilizada a razão de concentração de ordem k. Segundo Resende e Boff (2002, p. 77), é um índice positivo que fornece a parcela de mercado das $\mathrm{k}$ maiores empresas da indústria $(\mathrm{k}=1,2, \ldots, \mathrm{n})$, pode ser representado pela expressão: 


$$
C R(k)=\sum_{i=1}^{k} s_{i}
$$

Temos que:

$\mathrm{K}$ = número de firmas que fazem parte do cálculo;

$\mathrm{S}_{\mathrm{i}}=$ participação da i-ésima firma no mercado.

Quanto maior for o índice, maior é o poder de mercado exercido pelas k maiores empresas, e menor é o grau de concorrência entre as empresas. As razões de concentração utilizadas foram CR (4) e CR (8). Entretanto, há algumas falhas ao analisar os índices CR (k). Primeiro, por ignorar a presença das n-k empresas menores da indústria. Assim, fusões horizontais ou transferências de mercado que ocorrem entre elas não alteraram o valor do índice. Segundo, por não considerar a participação relativa de cada empresa no grupo das k maiores. Desse modo, importantes transferências de mercado que ocorreram no interior do grupo não afetaram a concentração medida pelo índice Resende e Boff (2002, p. 77).

No presente trabalho, a participação das firmas é medida pela recepção de leite dos maiores laticínios em função da industrialização de leite. Outra questão analisada, o uso desse índice para acompanhar a evolução da estrutura industrial pode levar a inconsistências de natureza, pois as $\mathrm{k}$ empresas de referência inicial pode não ser as mesmas entre os períodos.

Para análise dos resultados do índice de concentração de mercado, foi utilizada a classificação proposta por Bain (1968 apud MARION FILHO; LOPES), que se utiliza das quatro maiores empresas do setor e classifica os mercados como: CR (4) igual ou superior a $75 \%$ do mercado, oligopólio altamente concentrado; CR(4) entre $50 \%$ e $74 \%$, oligopólio moderadamente concentrado; CR (4) entre $25 \%$ e $49 \%$, oligopólio pouco concentrado; e CR (4) menor que 25\%, atomístico. Para o cálculo, optou-se pelos dados de recepção de leite por empresa com dados da Embrapa e do Leite Brasil.

\subsubsection{A conduta}

A conduta das empresas analisadas tem por base as estratégias de Porter (2004): liderança de custo, diferenciação e enfoque. A estratégia de liderança de custos é analisada por meio dos indicadores de margem de custos; por sua vez, as estratégias de diferenciação e enfoque são analisadas utilizando revisão bibliográfica de Wilkinson (2008), no relatório do projeto "Estudo sobre como as empresas 
brasileiras nos diferentes setores industriais acumulam conhecimento para realizar inovação tecnológica" da ABDI (2005).

\subsubsection{Indicadores de margem de custos}

As margens sobre os custos denotam as vantagens de custo das empresas, derivadas de vantagens operacionais ou de comercialização. Quanto menores as margens, maiores as vantagens. Por outro lado, revela as desvantagens das empresas marginais, as quais devem buscar estratégias de imitação para manterem suas parcelas de mercado. Os indicadores de custo a serem utilizados na caracterização da estrutura de custo das empresas seguem a nomenclatura e a forma de agregação utilizada pelo IBGE em pesquisas industriais anuais. Os itens de despesas considerados como custos e despesas totais de produção (CDT) são: gastos de pessoal (GP), os quais incluem salários, retiradas e outras remunerações (S), previdência social (PS), previdência privada (PP), FGTS, indenizações trabalhistas (IT) e benefícios (B); consumo de matérias-primas, materiais auxiliares e componentes (M); custo das mercadorias adquiridas para revenda $(\mathrm{R})$; compra de energia elétrica $\mathrm{e}$ consumo de combustíveis (EC); consumo de peças, acessórios e pequenas ferramentas (PF); serviços industriais prestados por terceiros e de manutenção (ST); aluguéis e arrendamentos (A); despesas com arrendamento mercantil (AM); impostos e taxas (T); depreciação (Dp); demais custos e despesas operacionais (DDO) e; despesas não-operacionais (DNO).

Os custos das operações industriais (COI) são os valores dos custos, na empresa, diretamente envolvidos na produção: consumo de matérias-primas, materiais auxiliares e componentes (M); compra de energia elétrica e consumo de combustíveis (EC); compra de peças e acessórios (PF); e serviços industriais e de manutenção e reparação de máquinas e equipamentos ligados à produção prestada por terceiros (ST). Dessa definição excluem-se os gastos com salários e encargos (GP). Essa desagregação é necessária para o cálculo das diversas margens de custos de produção; de outro lado, o COI é o agregado relativo ao pagamento de fatores de produção que não constituem o valor adicionado no processo produtivo da empresa. Assim, o COI é expresso por: $\mathrm{COI}=S T+P F+E C+M$.

As margens de custos de produção representam a participação desses custos no Valor Bruto da Produção Industrial (VBPI), cuja vantagem significativa indicaria economias de tamanho no âmbito da produção. Os indicadores seguem a definição de Possas (1978, p.18); a margem de custo de matérias-primas, ausente neste, foi definida de forma similar (LEMOS, 1992) somente trabalha com as margens de trabalho e de produção). 
Os custos de produção $(\mathrm{CP})$ são a soma dos custos das operações industriais com os gastos de pessoal: $C P=C O I+G P$

Os indicadores de margens de custos são definidos como:

1) Margem de custos de operação: $M C O=C O I / V B P I$

2) Margem de custos de matérias-primas: $M C M=M / V B P I$

3) Margem de custos de trabalho: $M C T=G P / V B P I$

4) Margem de custos de produção: $M C P=C P / V B P I$

\subsubsection{O desempenho}

A metodologia utilizada para a análise do desempenho tem por base os indicadores de produtividade e rentabilidade.

\subsubsection{Indicadores de produtividade}

Os indicadores de produtividade são calculados em termos de valor adicionado (VA) por pessoa ocupada, ou seja, são medidos pela capacidade do recurso humano de agregar valor ao produto; foi calculada a produtividade por pessoal total (POT); toma-se o Valor da Transformação Industrial (VTI) como proxy do VA. Os indicadores seguem definição dada por Possas (1978, p. 20). Assim,

Produtividade do trabalho Total: $P R O D T=V T I / P O T$.

\subsubsection{Indicadores de rentabilidade}

A rentabilidade da indústria pode ser mensurada de duas formas. De um lado, pelas margens de lucro, relação entre lucros e receita, que mostram a efetiva retenção de lucros das empresas da indústria em seu aspecto global, antes da dedução do imposto de renda e após o pagamento de todos os fatores produtivos e serviços utilizados.

De outro, pela rentabilidade corrente na produção, em que as margens de excedente, relação entre excedente e valor adicionado, sendo o primeiro a parcela do segundo não comprometido com os gastos com o trabalho, e o mark-up mostram a capacidade das empresas da indústria de agregar valor à sua produção, independentemente se essa agregação é interna ou externamente apropriada. Com base em indicadores de rentabilidade corrente na produção, é possível perceber a capacidade das empresas de agregar valor à produção, enquanto os índices de rentabilidade global mostram o que, efetivamente, é retido por elas, após a apropriação de parte desse valor agregado por terceiros. 
Os indicadores de rentabilidade corrente na produção envolvem o conceito de excedente, o qual representa a parcela da produção que é apropriada pela empresa, quando descontados o pagamento dos fatores diretos de produção, a saber, a matéria-prima, a energia e os combustíveis consumidos, a manutenção e o pessoal utilizado na produção, os quais totalizam o somatório do COI, mais salários na produção, caso em que se tem o excedente bruto; quando descontados, adicionalmente, os encargos trabalhistas, totalizando os custos de produção, o excedente passa a ser líquido, representando o valor adicionado líquido pela produção. A capacidade das empresas gerarem excedente pelo processo produtivo pode ser mensurada pelas margens de excedente, como segue, conforme Possas (1977, p. 21):

1) Margem líquida de excedente: $M L E=E L / V T I$

Em que MLE é a margem líquida de excedente; EL, o excedente líquido, diferença entre o valor adicionado, aqui tomado como proxy o VTI, e os gastos de pessoal: $E L=V T I-G P=V B P I-C P$.

2) Margem de lucro da produção: $M L P=L P / R L V I$

Em que LP é o lucro da produção; diferença entre a receita líquida de vendas de atividades industriais e o custo de produção: $L P=R L V I-C P$.

3) $M A R K U P=E L / C P$

O mark-up, relação entre preço e custo direto, é um indicador precioso da estrutura de mercado: de um lado, é uma indicação da proporção dos custos indiretos com os diretos; de outro, quando acompanhado de altas margens de lucro, é um indicativo do poder de fixação de preços das empresas, característica de estruturas de mercado oligopolizadas.

O cálculo e a análise desses indicadores podem mostrar, parcialmente, a evolução do comportamento da indústria de laticínios nos principais estados (Minas Gerais, Rio Grande do Sul e Santa Catarina) e no Brasil. Esses estados fazem parte dos cinco maiores produtores de leite no Brasil. Em função da indisponibilidade de dados, o estado de Goiás (estado que entrou em destaque na produção nos últimos anos) não fez parte da análise. Os indicadores foram calculados para os anos 1996 - 2010, cujos dados estavam disponíveis no IBGE.

\section{Resultados e discussão}

A análise de resultados e discussão foi dividida em análise da estrutura, da conduta e do desempenho. Para tanto, foram analisados e interpretados os resultados dos indicadores estruturais, de conduta e de desempenho da indústria. Foi avaliado o comportamento evolutivo dos indicadores de desempenho para os estados 
de Santa Catarina e Rio Grande do Sul e, de forma geral, para o Brasil, ao que incluiu-se a razão de concentração.

\subsection{A estrutura - razão de concentração da agroindústria de laticínios}

A agroindústria de laticínios brasileira, medida pelo CR (4), pode ser caracterizada por apresentar média concentração de mercado. Nesse sentido, a tendência da participação do mercado das quatro maiores empresas apresentou momentos de queda como de elevação, podendo ser considerado como um mercado de oligopólio pouco concentrado, ou seja, possui uma estrutura pouco concentrada com possibilidade de crescimento de firmas intermediárias e a entrada de firmas marginais.

Gráfico 1 - Razão de concentração para a agroindústria de laticínios 1996 - 2010

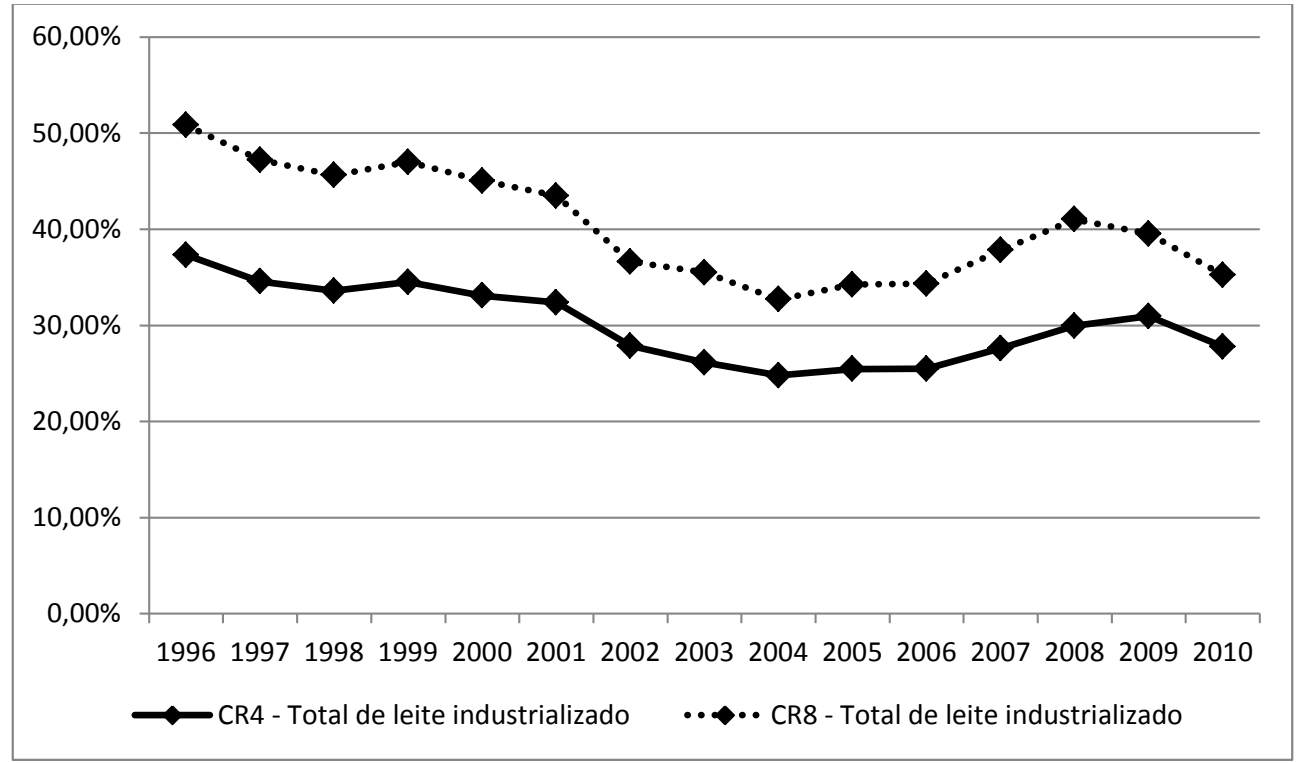

* Quantidade de leite cru, resfriado ou não, industrializado entre os anos 1997 a 2010.

*Leite pasteurizado no ano de 1996.

Fonte: elaboração própria a partir de dados da Embrapa e Leite Brasil.

A participação das oito maiores empresas no mercado, no ano de 1996, que era de $50 \%$, decaiu para $32 \%$ em 2004, atingindo $35 \%$ em 2010 . O índice das quatro maiores segue a mesma tendência, com participação de 37\% em 1996 e $24 \%$ em 
2004 e, em 2010, as quatro maiores empresas detinham $27 \%$ de mercado. Um dos motivos que desencadeiam essa mudança de participação de mercado ao longo do período pode estar relacionado ao crescimento de empresas intermediárias que colaboraram para a desconcentração do mercado, principalmente no período de 2001 a 2004. Durante o período de 1996 a 2010, houve mudança contínua no ranking das maiores empresas, pela análise de recepção de leite por empresa. Apenas a DPA (marca Nestlé) mantém-se em primeiro lugar em todo o período de estudo. Já a Itambé que era segunda no ranking até 2005 passa a ser terceira a partir de 2006.

Destaca-se que os processos de fusões e aquisições, ocorridos na década de 1990, foram marcados pela aquisição de empresas marginais e marcas regionais. Cabe ressaltar que, no período 1996 a 2001, ocorreram apenas quatro fusões e aquisições (em 1998, a Ivoti passou para o controle da Milkaut, a Batavo para a Parmalat; em 1999 a Queijo Minas passou para o controle da Perez Companc, a Mococa para Royal Numico) lembrando que outras 20 fusões e aquisições já haviam ocorrido entre os anos de 1990 a 1996.

Na última década, novamente ocorreram processos de fusões e aquisições que modificaram a estrutura do mercado, como no caso da fusão entre as empresas Perdigão e Sadia, formando a BRF - Brasil Foods, em 2009, e o caso da criação da empresa Lácteos Brasil (LBR), pela fusão, em 2010, da LeiteBom e da Bom Gosto, que reuniu as marcas Parmalat, LeiteBom, Paulista, Poços de Caldas, Glória, Boa Nata, Bom Gosto, Líder, Cedrense, DaMatta, São Gabriel, Sarita, Corlac e Ibituruna.

\subsection{A conduta - resultados dos indicadores técnico-econômicos e estratégias das empresas}

$\mathrm{Na}$ análise, foram feitas comparações entre os indicadores de cada estado e o Brasil para entender as diferenças e identificar quais estados possuem vantagem. Para tal análise, tomou-se por base a eficiência produtiva com relação a esses indicadores, buscando-se um reflexão em torno de maiores margens de lucro ou menores margens de custos. Também foram verificadas mudanças significativas, no decorrer do período, relacionadas com a estrutura de mercado, bem como se investigou quais as possíveis causas dessas mudanças. Além disso, foram apresentadas às estratégias dos principais laticínios no Brasil. 


\subsubsection{Indicadores de margem de custos}

O Gráfico 2 representa as margens de custos de operações industriais que dizem respeito à participação desses no VBPI. São os valores dos custos nas empresas diretamente envolvidos na produção, diminuindo os gastos com pessoal, as margens desses custos tiveram leve queda na média nacional, entre 1996 a 2000. Entretanto, no período de 2001 a 2010, houve elevação nas margens desses custos para o Brasil nos cinco primeiros anos, e, posteriormente, em 2010, ocorre um retorno aos mesmos níveis apresentados em 1996. Essas margens de custos tem grande influência dos preços do leite pago ao produtor.

Gráfico 2 - Margem de custos de operação da indústria de laticínios 1996-2010

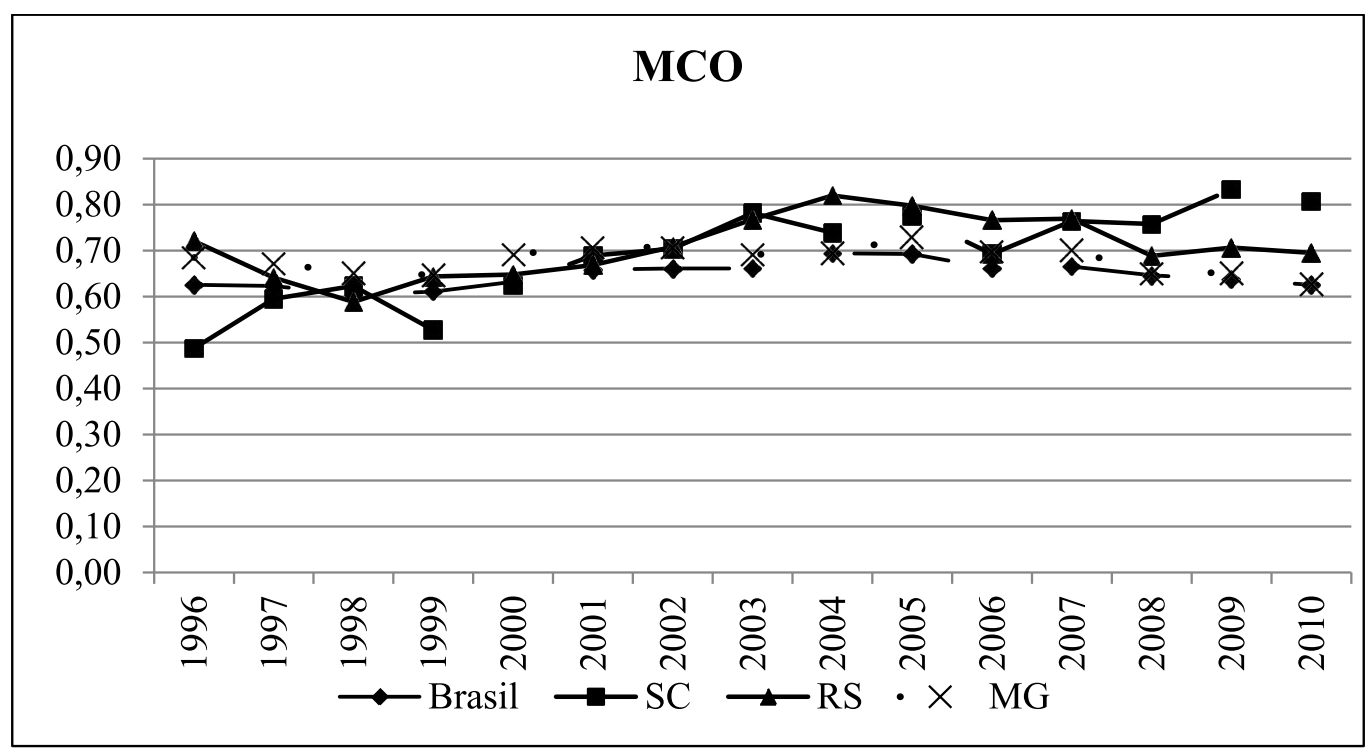

Fonte: elaboração própria a partir de dados do IBGE

Esse desempenho está relacionado não só com os menores custos na aquisição da matéria-prima. Segundo Melo (2002), três quartos dos custos industriais provêm da matéria-prima, tanto pode ser leite natural como beneficiado pela indústria de processamento primário. Esses custos decresceram em cerca de $2 \%$ ao ano entre 1990 e 1999, porém, em função do maior aumento do valor bruto da produção industrial do que o aumento dos custos das operações industriais. Isso pode ter como hipótese o maior valor dos produtos derivados do leite. 
Nota-se pelos resultados obtidos que a média nacional possui as margens mais baixas que os estados do Rio Grande do Sul e Santa Catarina, mas em comparação com as margens de custos de Minas Gerais são quase iguais. Para o período de 2007 a 2010, houve um deslocamento nas margens de custos para o estado de Santa Catarina, ficando em desvantagem perante o mercado nacional nas margens de custos.

O Gráfico 3 mostra os resultados das margens de custos com a matéria-prima, o qual apresenta uma tendência de queda nos dois primeiros anos, e, uma elevação no período posterior, compreendido até 2005. Importante observar que, enquanto para o Rio Grande do Sul, Minas Gerais e para a média nacional houve o declínio das margens desses custos de forma acentuada, de 2005 a 2010, Santa Catarina apresentou margens elevadas. Os custos menores de 1996 a 1998 têm por hipótese os menores custos, seja com leite in natura ou beneficiado pela indústria de processamento primário que, como visto, tiveram em queda nesse período.

Gráfico 3 - Margem de custos com matérias-primas da indústria de laticínios 1996-2010

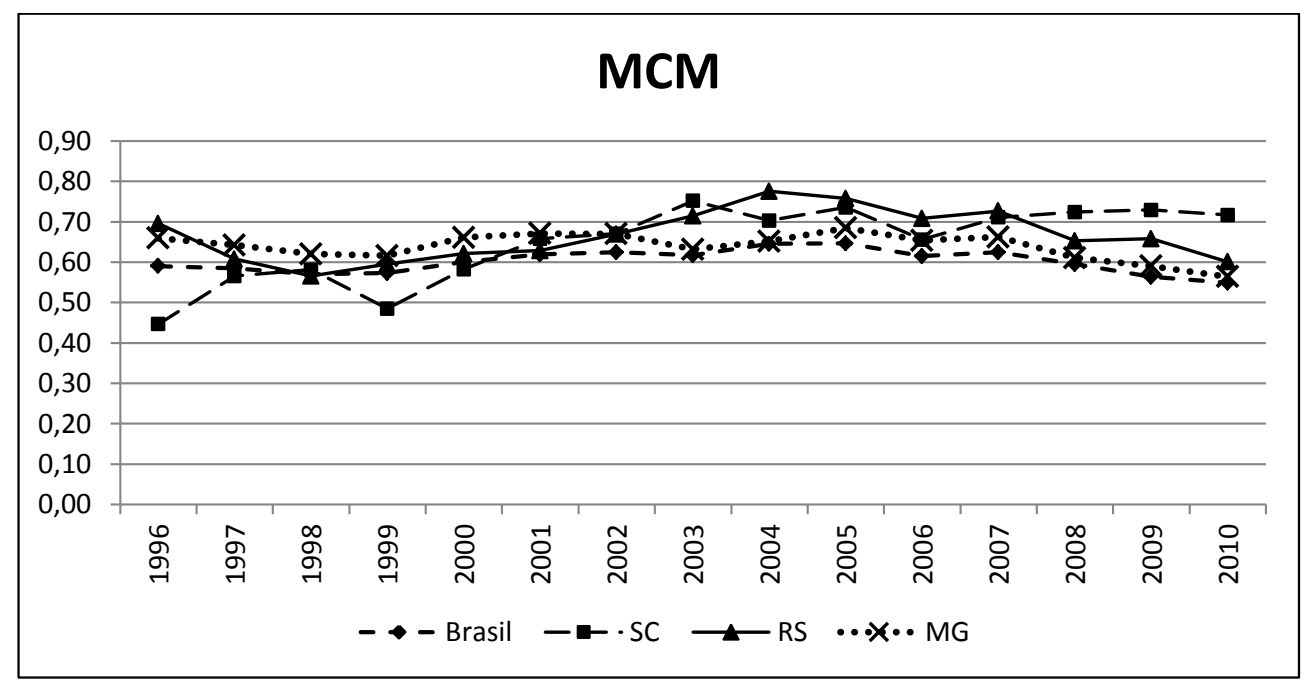

Fonte: elaboração própria a partir de dados do IBGE.

Após 1998, revela-se uma tendência de crescimento nas margens de custos com matéria-prima até 2005 , fato que pode estar relacionado a dois fatores: a diminuição das importações e o início das exportações, a partir do ano 2000. Isso ocorreu, possivelmente, pela desvalorização cambial que tornou o produto brasileiro mais competitivo e pelo aumento do consumo que faz aumentar a competição por 
parte das empresas pela matéria-prima, leite, encarecendo seus custos pelo pagamento maior dos preços aos seus fornecedores.

O Gráfico 4 está representando os gastos com salários, retiradas e outras remunerações, encargos sociais e trabalhistas, indenizações e benefícios. A indústria de laticínios apresentou queda ao decorrer do período para os estados analisados e o Brasil como um todo. Isso se explica pela diminuição do quadro de funcionários empregados pela indústria, principalmente, para o período dos anos de 1990, como também, pela criação de novas unidades empresariais. Outro fator pode estar relacionado à maior eficiência produtiva das empresas por razão do uso de tecnologias mais avançadas, agregando valor aos produtos. Isso se deve, em parte, pela desregulamentação da economia que permitiu que as empresas investissem em modernização. Além disso, a abertura econômica permitiu a entrada de empresas estrangeiras que possuem bases tecnológicas mais eficientes no processamento. No Rio Grande do Sul, o quadro de pessoal aumentou no período de 1996 a 2000 (exceção de 1999). Mesmo assim, houve queda na margem de custos com trabalho, e isso está relacionado ao maior crescimento do valor médio da produção industrial por estabelecimento, gerando um valor bruto da produção industrial, refletindo de forma acentuada no desempenho da agroindústria láctea.

Gráfico 4 - Margem de custos de trabalho na indústria de laticínios 1996-2010

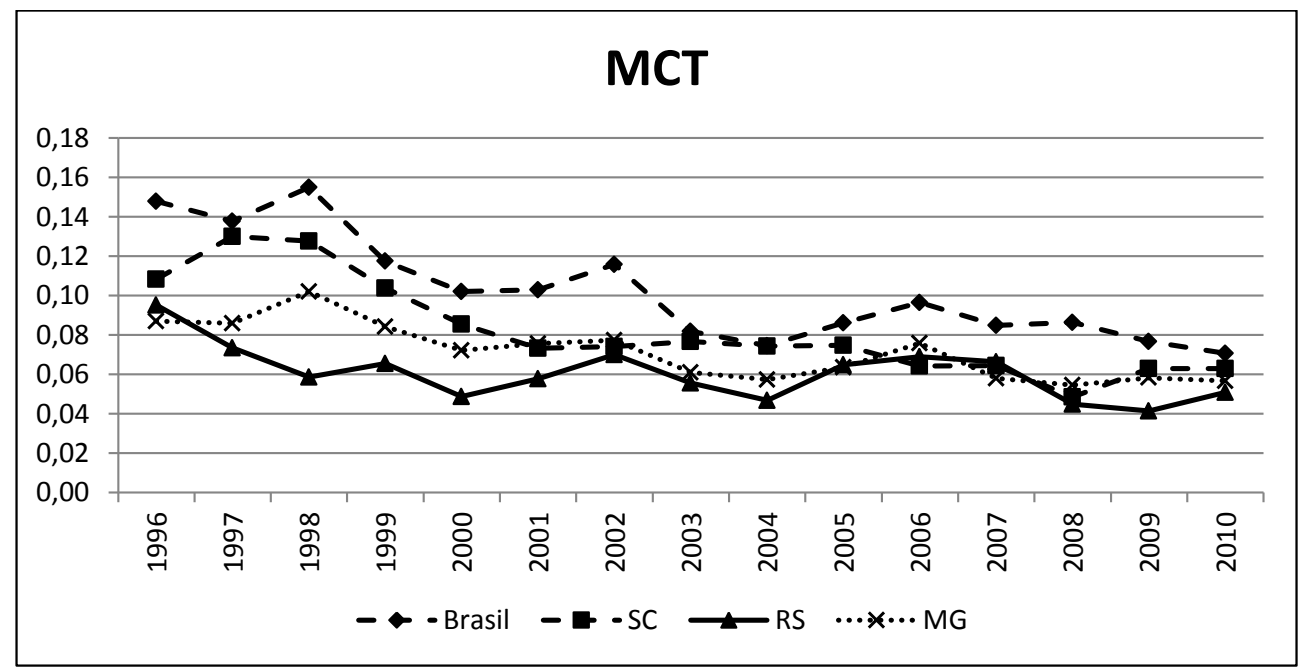

Fonte: elaboração própria a partir de dados do IBGE. 
Quanto às margens de custos de produção, representado pelo Gráfico 5, que envolve os custos de operações industriais e gastos com pessoal sobre o VBPI, percebe-se a desvantagem das agroindústrias do estado de Santa Catarina, no período mais recente, de 2007 a 2010. Isso é um reflexo tanto das MCO como também das MCM em praticamente todo o período em análise, ficando com custos acima da média nacional. Na década de 1990, o estado tinha vantagens sobre as margens de custos. O Rio Grande do Sul teve vantagens para o período de 1997 a 2002, mas apresenta média superior a nacional de 2002 a 2010. Minas Gerais foi o estado que apresentou vantagens sobre os outros estados nas margens de custos, principalmente, a partir de 2003. Os fatores que explicam as desvantagens de custos de produção tanto de Santa Catarina quanto do RS são as maiores margens de custos com operações industriais, principalmente, matérias-primas, pois as margens de custos com trabalho são menores em relação à média nacional. Para todo o período em análise, diminuíram as margens de custos com a produção nos estados do Rio Grande do Sul e Minas Gerais e também na média nacional; para Santa Catarina, ocorreu um processo de desvantagens quanto às margens de custos, refletindo diretamente no resultado do mark-up para as empresas, como pode ser visto pelo Gráfico 9.

Gráfico 5 - Margem de custos de produção da indústria de laticínios 1996-2010

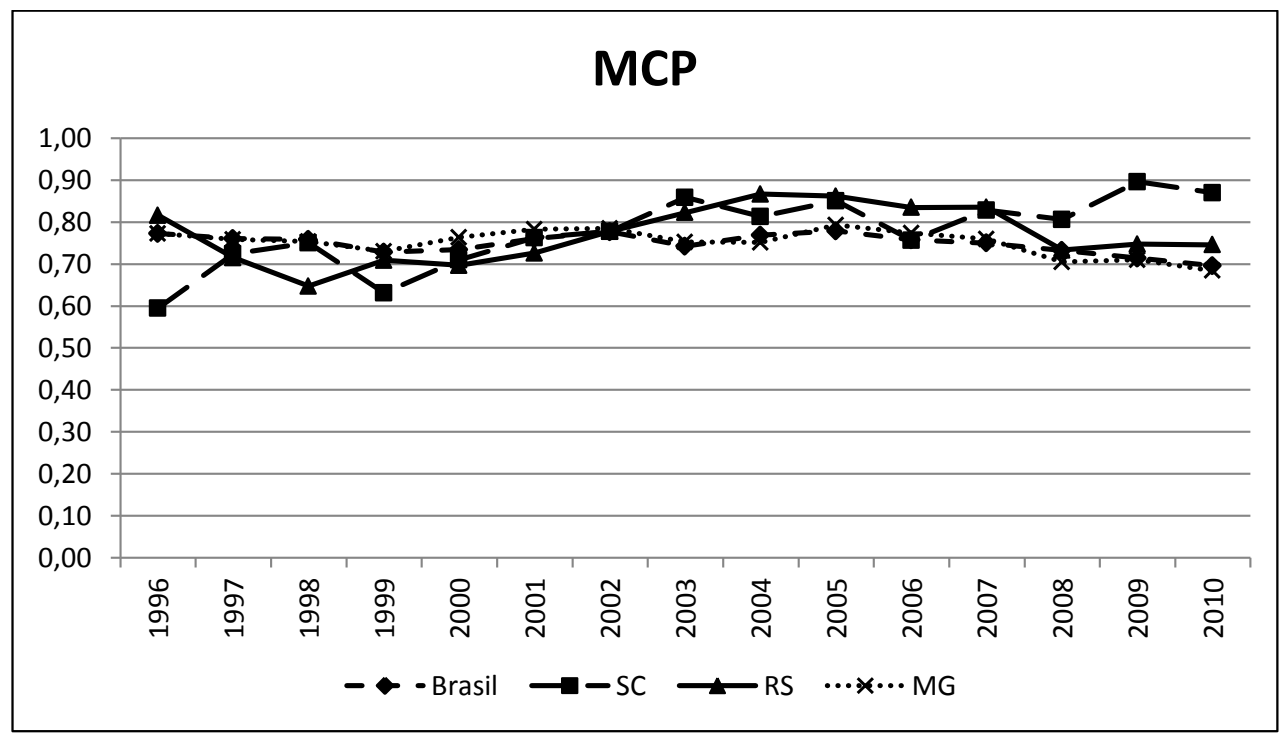

Fonte: elaboração própria a partir de dados do IBGE. 


\subsubsection{As estratégias adotadas pelas empresas}

\subsubsection{A estratégia da liderança de custo}

Conforme relatório da ABDI (2005, p. 107), no setor de lácteos as "empresas são competitivas, principalmente pela economia de escala e conseguem estabelecer certo domínio de mercado devido a essas reduções de custos". Assim, diante da análise dos custos pode-se mencionar que, na estratégia de liderança de custos, há claramente uma conduta de redução das margens de custos do trabalho, seguida de uma tentativa de redução ou manutenção das margens de custos das matérias-primas.

A conduta da redução da margem de custo do trabalho perpassa pela implantação da diminuição do pessoal ocupado nas empresas e pelo aumento do pessoal ocupado na produção, reduzindo, dessa forma, o número de pessoas que não têm relação direta com a produção. A conduta de redução ou manutenção da margem de custo das matérias-primas está intimamente ligada com o aumento do tamanho das plantas produtivas das empresas, atrelada, também, ao aumento do tamanho médio das fazendas produtoras de leite. Segundo Aguiar (2009), essa conduta visa reduzir o número de fornecedores e aumentar a quantidade média coletada por fornecedor. Assim, é possível reduzir os custos da produção de matéria-prima, além dos custos de coleta dessa matéria-prima.

\subsubsection{A estratégia de diferenciação}

Conforme a ABDI (2005), a diferenciação de produtos é amplamente utilizada por muitas empresas de diversos tamanhos, sendo integrada à comercialização e à produção. Assim, a diferenciação visa atender pequenas indústrias que atuam em poucos segmentos, esses estão, muitas vezes, voltados a mercados regionais específicos, bem como às grandes empresas nacionais que atuam em diversos segmentos do mercado de lácteos. Em consonância com o relatório da ABDI, Martins e Padula (2000) constataram que as pequenas empresas privilegiam uma estratégia de trabalhar em nichos de mercado, com pouca segmentação de mercado, mas sem deixar de diferenciar os seus produtos. As cooperativas por meio de uma escala maior buscam trabalhar com diversos produtos diferenciados em vários segmentos do mercado de lácteos.

Em relação à estratégia da diferenciação, é possível verificar claramente dois movimentos que podem ocorrer de forma separada ou conjunta, que são a 
diferenciação por meio da marca e do produto. Nesse sentido, diferentemente da estratégia de substituição da marca original pela da Parmalat, adotada na década de 1990, as fusões que ocorreram na década de 2000 mantiveram as marcas dos produtos originais, ou seja, a LBR manteve as marcas Boa Nata, Bom Gosto, DaMatta, Ibituruna, Leite Bom, Líder Alimentos, Parmalat e Poços de Caldas, bem como a BRF conservou as marcas Batavo, Cotochés e Elegê. Formula-se a hipótese de que essa nova estratégia nas fusões esteja vinculada ao valor de ativo que as marcas apresentam, pois tais marcas representam empresas adquiridas cujas marcas já estavam consolidadas não apenas em mercados locais e regionais. Outro fator que estimula a diferenciação de marca sem que haja uma diferenciação de produto está no fato de que uma empresa pode segmentar o mercado lácteo em diversas linhas de produtos, atuando com uma ou mais marcas nesses segmentos. Com isso, os produtos de características similares podem ser ofertados a diferentes níveis de renda com preços diferenciados.

A diferenciação de produto considera as especificidades regionais e o gosto dos consumidores atrelado ao poder de compra desses. Assim, é comum determinadas empresas diferenciarem seus produtos por meio de pequenas melhoras que passam pela diferenciação de embalagens; pela quantidade ofertada do produto por embalagem; da diversificação de sabores, consistências, enriquecimento com vitaminas, fibras e cálcio, no caso de bebidas lácteas e iogurtes; da oferta de leite nas formas UHT e leite em pó (integral,desnatado e semidesnatado); leites com ação probiótica; leites com enriquecimento de cálcio, vitaminas, colágeno ou fibras. Ainda pode ocorrer a diferenciação de marcas e produtos. Nesse sentido, as empresas trabalham no mesmo segmento de produtos com marcas diferentes e diferenciação de produtos.

Ressalta-se que, para algumas empresas e para determinados produtos, a estratégia da diferenciação de marcas não aumenta os custos de produção, tendo em vista que as técnicas de produção não se alteram na fabricação de uma ou de outra marca, apenas é alterado o rótulo do produto, podendo-se utilizar a mesma planta industrial para a fabricação de produtos de múltiplas marcas. Nesse sentido, as empresas permanecem com ganhos de escala na produção.

\subsubsection{A estratégia de enfoque}

A estratégia de enfoque é utilizada por pequenas e médias empresas e caracteriza-se em poucos segmentos de produtos lácteos, visando, com isso, atender alguma faixa de renda específica, algum mercado geográfico específico ou produzir com escala para reduzir os custos desses produtos. 
Destaca-se que a estratégia de enfoque pode ser utilizada na forma de empresas que atuam como atravessadoras entre a produção e a industrialização do leite. Assim, o enfoque dessas empresas é captar a maior quantidade possível de leite e vendê-lo a empresas que o industrializam, obtendo uma comissão de venda tanto dos produtores como dos laticínios que industrializam o leite.

\section{$5.3 \mathrm{O}$ desempenho - resultado dos indicadores de produtividade e rentabilidade}

A análise do desempenho será formada pelos indicadores de produtividade e de rentabilidade.

\subsubsection{Indicadores de produtividade}

Os indicadores de produtividade, apresentados no Gráfico 6, mostram a capacidade do recurso humano de agregar valor ao produto, configurando-se como um indicador de desempenho da indústria. Os resultados mostram uma tendência assimétrica entre os estados no primeiro período. De 1996 até 1999, apenas o Rio Grande do Sul obteve produtividade do trabalho crescente nesse período. Para o período de 1999 a 2005, houve diminuição, de modo geral, na indústria de processamento de laticínios para o Brasil e também para os estados analisados. Posteriormente, a indústria voltou a obter aumento da produtividade do trabalho, o que torna o setor com maior competitividade internacional.

Gráfico 6 - produtividade do trabalho da indústria de laticínios, $R \$ /$ trabalhador, 1996-2010

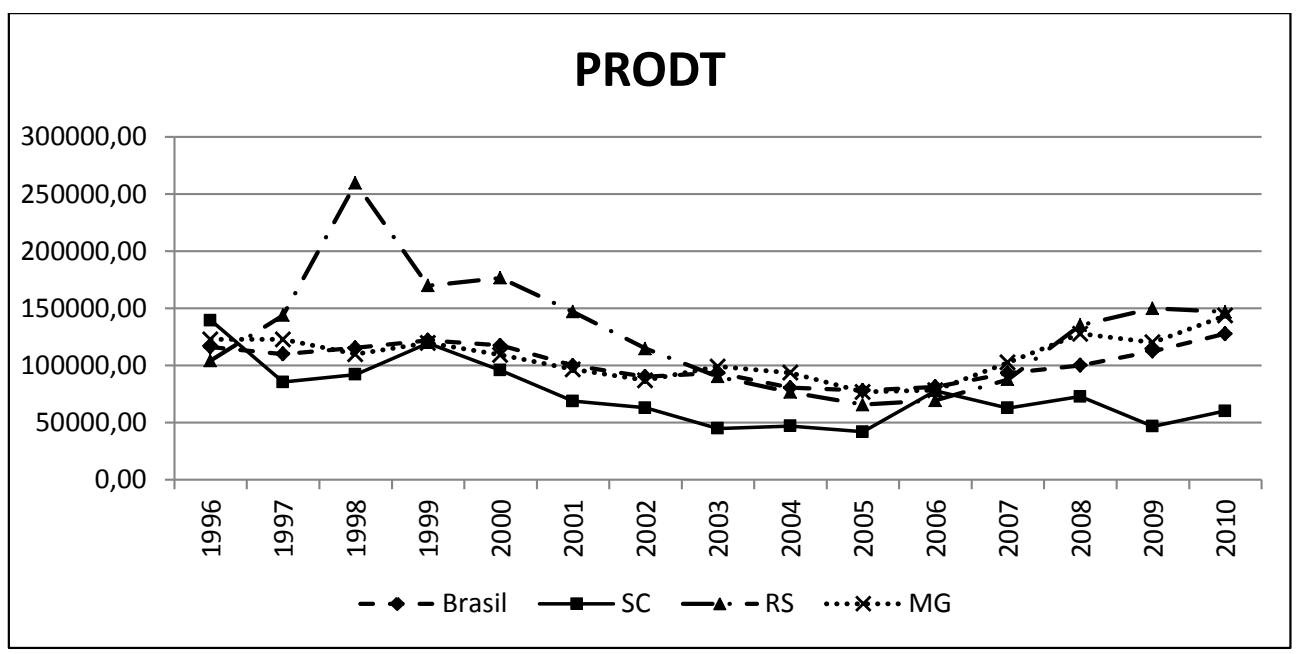

Fonte: elaboração própria a partir de dados do IBGE. 
Santa Catarina, com resultados inferiores para as margens de custos, também apresentou resultados inferiores para a produtividade do trabalho. Quanto à produtividade da indústria na média nacional e para os estados do Rio Grande do Sul e Minas Gerais, os quais apresentaram um crescimento mais significativo para o período, principalmente, após 2006. Um desempenho inferior para Santa Catarina ocorreu de 2000 a 2005 com uma queda acentuada na produtividade do trabalho.

O aumento da produtividade na década de 1990 pode estar aliado à abertura da economia. São vários os trabalhos que atribuíram o aumento da produtividade na indústria manufatureira à abertura econômica (MOREIRA, 1999-A, CARVALHO, 2000 apud FEIJÓ, 2003, p.20), a qual barateou o custo dos bens de capital e estimulou a concorrência entre produtores nacionais e estrangeiros, forçando a modernização. Outro fator que contribuiu para isso é o aumento da concentração na indústria, o que favorece o desenvolvimento tecnológico.

O grande aumento na produtividade do trabalho, para o estado do Rio Grande do Sul, entre 1996 e 1998, pode estar relacionado à compra da Lacesa pela Parmalat e, posteriormente, a venda da CCLG para o grupo Avipal. Tais acontecimentos caracterizaram o setor como oligopólio colusivo, em que mais de $70 \%$ da produção de leite do Estado passa ao domínio de dois grupos internacionais (BITENCOURT, 2000, p. 222).

Essa interpretação pode ser feita na comparação entre a razão de concentração calculada, representada no Gráfico 1, com o indicador de produtividade do trabalho em que ocorre uma relação bastante visível para o período de 2004 a 2009, quando as quatro maiores empresas detinham - em 2004 - 24\% do total de recepção de leite. Em 2009, esse índice passou para 30\%, enquanto a produtividade do trabalho era de $R \$ 80.525,78$ por trabalhador e passou a ser de $R \$ 112.371,73$, em 2009. Para melhores evidências, seria necessário calcular a concentração por estado, o que não foi realizado nessa pesquisa.

\subsubsection{Indicadores de rentabilidade}

Os gráficos abaixo mostram as características distintas de rentabilidade da indústria de laticínios nos diferentes estados do Brasil. 
Gráfico 7 - Margem líquida de excedente da indústria de laticínios 1996-2010



Fonte: elaboração própria a partir de dados do IBGE.

Observa-se, no Gráfico 7, aumento no desempenho na geração de excedente líquido na maior parte do período para os estados de Minas Gerais e o Rio Grande do Sul, de 1997 a 2002, e, posteriormente, de 2007 a 2010, ficando acima da média nacional na geração de valor agregado aos produtos lácteos pelas empresas. Enquanto o estado de Santa Catarina apresentou um resultado acima da média nacional no período de 1996 a 2002, mas com exceção de 2006 e 2008, ficou abaixo da média nacional. O que se percebe também é que, tanto a média nacional como o RS, apresentaram uma tendência de alta em agregar valor ao produto pelas empresas da indústria de laticínios, enquanto Santa Catarina diminuiu, principalmente, entre 2008 e 2009. Reflexo que pode advir da crise internacional do período.

O desempenho durante o período pode ser explicado pelo uso de novas técnicas no processamento de produtos lácteos de forma mais elaborados e o crescimento nas vendas desses produtos. Como, por exemplo, o leite UHT, iogurtes e bebidas lácteas que possuem um preço de venda maior que produtos tradicionais. 
Gráfico 8 - Margem de lucro de produção da indústria de laticínios 1996-2010

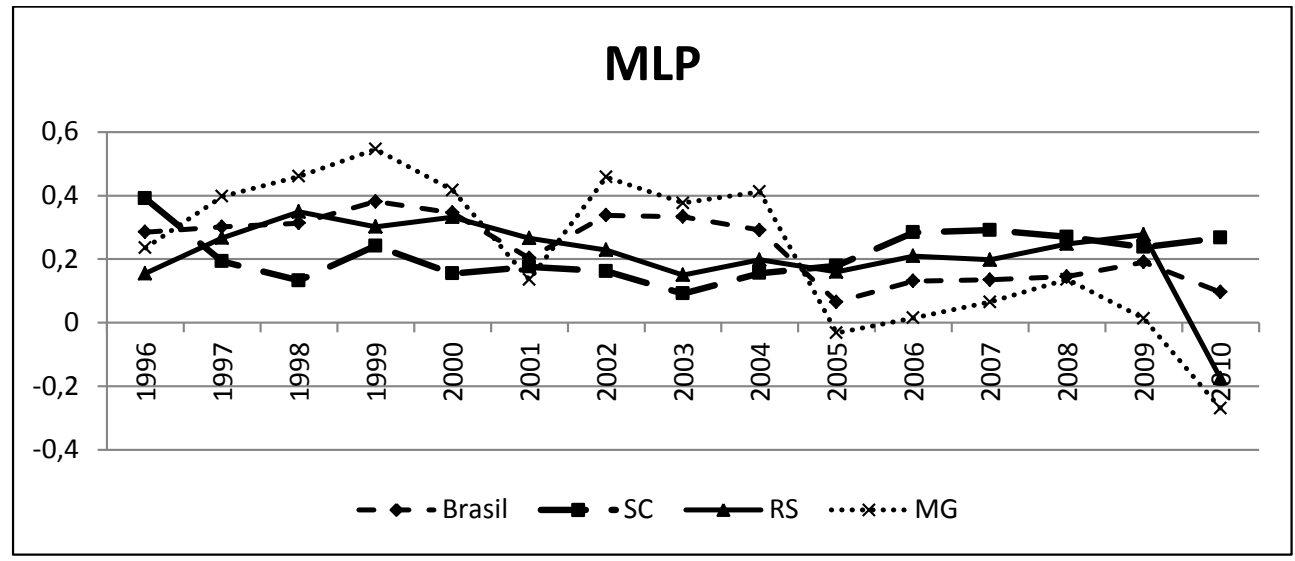

Fonte: elaboração própria a partir de dados do IBGE.

Verifica-se, no Gráfico 8, uma variação muito grande entre os estados com relação às margens de lucro da produção. As margens de lucro demonstram a retenção efetiva de lucros pelas empresas. Lucros maiores podem estar relacionados a menores custos de fatores de produção. Nota-se que há uma ascensão na média nacional até 1999 da retenção de lucro pelas empresas. Após esse período houve uma forte retração nas margens de lucro até 2001, voltando a crescer no período próximo. Uma característica importante é que há variabilidade tanto para média nacional como para os estados em análise.

O Estado de Santa Catarina mostra uma tendência de retenção dos lucros a partir de 2003. Em relação à média nacional, a tendência é de queda nas margens de lucro pelas empresas de laticínios. Para Minas Gerais, apresentaram resultados bastante variados, decrescendo no período em análise. Pode-se avaliar como valores atípicos para alguns anos. As empresas de laticínios do Rio Grande do Sul obtiveram, no período de 1996 a 2000, uma elevada margem de lucro, indicando aumento no desempenho nesse período com menores margens de custos de produção, maiores margens de excedente e maior produtividade do trabalho. Isso pode ter sido gerado, de forma particular, pelas grandes empresas atuantes que detinham alta concentração de mercado nesse Estado, um poder de fixar preços. Mas esse desempenho conquistado pelas empresas atuando em território gaúcho perde força após 1998 decrescendo constantemente suas margens de lucro, excedente e o mark-up. Isso pode ter como causa o próprio ajuste de mercado motivado pela concorrência. 
O mark-up apresentou uma dinâmica diferente entre os estados, principalmente para o período de 1996 a 2000, podendo ser reflexo dos ajustes do setor na década de 1990 em função das mudanças ocorridas tanto na economia como também no setor de lácteos. A partir de 1999, houve uma tendência de queda até o período de 2004, posteriormente revertido, tanto para a média nacional como o Rio Grande do Sul e Minas Gerais. O estado de Santa Catarina teve ascensão em 2006, mas volta a registrar queda a partir desse ano. Enquanto isso, os estados do RS e Minas Gerais assim como a média nacional recuperam-se, fechando o período de 2010 com mark-up superior ao inicial de 1996. Em relação ao mark-up para as empresas do Brasil. Destaca-se, ainda, que, a partir de 2008, ocorreram grandes fusões no setor de laticínios o que, por sua vez, permite que empresas como a Nestlé, Brasil Foods e LBR - Lácteos atuassem no mercado com um grau maior de diferenciação de produtos e marcas, contribuindo, desta forma, para elevar o mark-up em nível de Brasil.

Gráfico 9 - Mark-up da indústria de laticínios 1996-2010

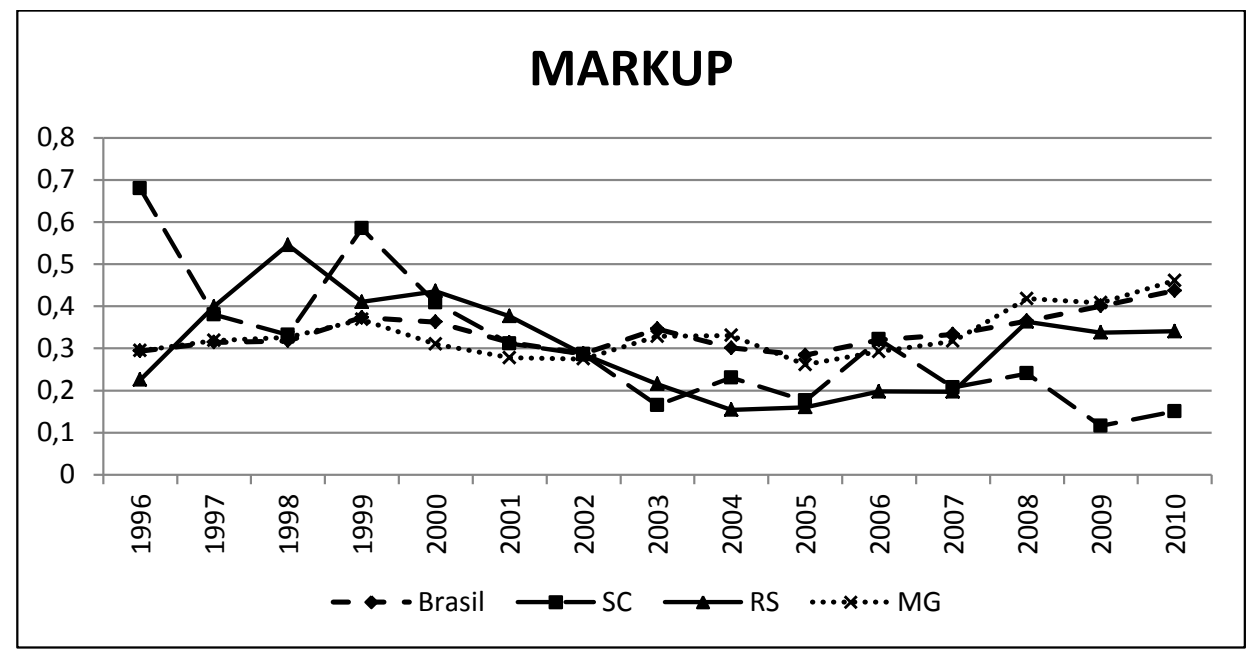

Fonte: elaboração própria a partir de dados do IBGE.

Pelos dados verifica-se que o Rio Grande do Sul e Minas Gerais mantiveram resultados melhores pela rentabilidade corrente na produção e o mark-up em praticamente todo o período em relação a Santa Catarina. Minas Gerais, por ser o maior estado produto, tem uma tendência bastante próxima à média nacional nos indicadores. Importante destacar que, praticamente todos os indicadores, da média nacional, apresentaram melhoria para o período em análise; apenas a margem de lucro de produção teve redução no período final. 
Para os indicadores de margens sobre os custos de produção, enquanto a média nacional da indústria permaneceu a mesma, se comparado o período final com o inicial, para o estado de Santa Catarina, houve um aumento; o Rio Grande do Sul e Minas Gerais obtiveram redução, demonstrando vantagens em relação a esse indicador. Quanto à produtividade do trabalho, tanto para o Brasil, quanto para os estados em particular obtiveram melhora.

Quanto aos indicadores de rentabilidade, percebe-se uma variabilidade muito grande tanto em relação a período como em relação aos estados pesquisados e para a média nacional. Enquanto o desempenho para a média nacional na margem líquida de excedente e no mark-up aumentaram, a margem de lucro diminuiu. Para os estados analisados, a margem líquida de excedente e o mark-up aumentaram para o Rio Grande do Sul e Minas Gerais, porém, Santa Catarina teve apenas uma maior margem de lucro.

\section{Considerações finais}

A economia brasileira foi marcada na década de 1990 por profundas mudanças que impactaram na agroindústria do agronegócio brasileiro, de forma específica sobre agroindústria de laticínios. Essas mudanças dizem respeito à abertura econômica, formação do Mercosul, desregulamentação do mercado de laticínios e a estabilização econômica com a adoção do Plano Real, facilitando um fluxo maior de bens e serviços como também de capital.

A partir dessas mudanças, ocorreu uma reestruturação agroindustrial no Brasil: com a necessidade de obter lucro, as empresas passaram a diversificar sua produção e diferenciar seus produtos. Além disso, na década de 1990, ocorreu concentração de capital nos diferentes segmentos do sistema agroindustrial pelo processo de fusões e aquisições promovidos por meio do capital externo, processo que levou à desnacionalização agroindustrial.

A partir de 1990, ocorreram grandes mudanças estruturais da indústria de laticínios no Brasil. Empresas multinacionais instalaram-se no país e as que estavam ampliaram sua participação no mercado pelo processo de fusões e aquisições. Essas mudanças continuaram no período recente verificado pela fusão da Perdigão com a Sadia e do Leite Bom com a Bom Gosto. Diferentemente da estratégia adotada, na década de 1990, de substituição da marca original pela da empresa multinacional, as fusões que ocorreram na década de 2000 mantiveram as marcas dos produtos originais, isso, por sua vez, demonstra que essa nova estratégia nas fusões esteja vinculada ao valor de ativo que as marcas apresentam, pois essas 
marcas que representam empresas adquiridas cujas marcas já estavam consolidadas não apenas em mercados locais e regionais. As empresas também passaram a competir por fornecedores que ofereceriam maiores volumes de produção diária de leite e melhor qualidade, acarretando queda do número de fornecedores.

Com o início da fabricação do leite Longa Vida, nos anos 90, decorreu uma melhor eficiência no setor por oferecer maior prazo de validade, facilidade de distribuição e redução de custos na comercialização. Por meio de mudanças institucionais, ocorridas na década de 1990, a abertura comercial propiciou o fluxo de capitais externos responsáveis pelas aquisições. Com a desregulamentação do mercado leiteiro, fez crescer os incentivos para entrada de empresas multinacionais na economia brasileira em busca de maiores lucros com a fabricação de novos produtos.

A agroindústria de laticínios brasileira passou por um período de desconcentração que foi de 1996 até 2005 e, então, voltou a aumentar a participação das quatro e das oito maiores empresas, chegando a um máximo em 2008, período em que ocorreu a crise dos Estados Unidos. Apresentou, para o período, uma estrutura, medida pela razão de concentração, de oligopólio pouco concentrado. Tal situação mostrou que a estrutura industrial de laticínios é pouco concentrada com possibilidade de crescimento de firmas intermediárias e a entrada de firmas marginais.

$\mathrm{Na}$ avaliação dos indicadores, calculados entre 1996 a 2010, aumentou o desempenho, principalmente, nas margens de custos com trabalho, produtividade do trabalho e nas margens de excedente líquido. Também houve uma leve queda nas margens de custos com a produção da indústria de laticínios brasileira, refletindo em maior mark-up. Esse desempenho pode estar relacionado não apenas à estrutura, mas às mudanças institucionais e tecnológicas da agroindústria láctea, que decorreram na década de 1990 e na primeira década desse século.

As margens de custos de operações, da agroindústria láctea nacional, apresentaram queda entre 1996 a 1998 elevando-se após esse período, fechando em 2010 com margens de custos estáveis em relação a 1996. Santa Catarina e Rio Grande do Sul ficaram em desvantagem em relação à média nacional para o período em análise, enquanto Minas Gerais mostrou-se com menores margens de custos.

Os resultados da produtividade do trabalho mostram uma tendência assimétrica entre os estados no primeiro período, de 1996 até 1999: apenas o Rio Grande do Sul obteve produtividade do trabalho crescente nesse período. Para o período de 1999 a 2005, houve diminuição de modo geral na indústria de processamento de laticínios para o Brasil e também para os estados analisados. Posteriormente a indústria láctea volta a obter aumento da produtividade do trabalho o que torna o setor com maior competitividade internacional. 
Pelos indicadores de rentabilidade, apenas as margens de excedente líquido apresenta uma nítida tendência de alta, em que o Rio Grande do Sul, Minas Gerais e a média brasileira apresentaram aumento. A elevação na geração de excedente pode ser explicada pelo lançamento de novos produtos mais elaborados com maior valor agregado em que substituíram os tradicionais.

Nas margens de lucro e no mark-up, houve uma variação muito grande durante o período. A geração do mark-up está relacionada com as margens de custos e a diferenciação de produtos e marcas. Assim, houve uma melhora nesse indicador para a média nacional, principalmente, a partir de 2004. Somente Santa Catarina apresentou maior retenção de lucros teve declínio quanto ao mark-up.

Por fim, conforme os resultados apresentados há uma assimetria entre os estados analisados e esses em relação ao Brasil, ao menos nas variáveis estudadas. Mas em geral, a agroindústria de laticínios do Brasil apresentou ascensão em seus indicadores de desempenho. 


\title{
The evolution of dairy agribusiness in Brazil based on the indicators of the structure, conduct and performance
}

\begin{abstract}
This article analyzes the structural changes in the dairy industry in Brazil and in the states of RS, SC and MG in the period 1996-2010. Its model SCP method to check the evolution of the structure by calculating the concentration ratio and technical-economic indicators, as well as strategies for the analysis of Porter's conduct and performance of dairy agribusiness. The results show a little concentrated oligopoly structure with margins stable costs of production. Regarding the evolution of conduct can be said that there was diversification of production and product differentiation. The performance analysis showed that there was an improvement in productive efficiency both for Brazil and for the states surveyed, demonstrated by the increase in labor productivity. The state of SC had increased performance in labor productivity and profit retention. The states of RS and MG showed greater productive efficiency in other indicators reflecting superior performance compared to SC.
\end{abstract}

Keywords: Structural evolution. Performance of technical and economic indicators.

\section{La evolución de la agroindustria láctea en Brasil basado en los indicadores de la estructura, conducta y desempeño}

\section{Resumen}

Este artículo analiza los cambios estructurales en la industria lechera en Brasil y en los estados de RS, SC y MG en el período 1996-2010. Su método modelo ECD para comprobar la evolución de la estructura mediante el cálculo del coeficiente de concentración y los indicadores técnico-económicos, así como las estrategias para el análisis de la conducta y el desempeño de la agroindustria láctea de Porter. Los resultados muestran una pequeña estructura de oligopolio concentrado, con márgenes estables de los costos de producción. En cuanto a la evolución de la conducta se puede decir que no era la diversificación de la producción y diferenciación de productos. El análisis de rendimiento mostró que hubo una mejora en la eficiencia productiva tanto para Brasil como para los estados encuestados, lo demuestra el aumento de la productividad laboral. El estado de Carolina del Sur ha aumentado el rendimiento de la productividad laboral y la retención de beneficios. Los estados de RS y MG mostraron una mayor eficiencia productiva en otros indicadores que reflejan un rendimiento superior en comparación con el SC.

Palabras clave: Evolución estructural. El desempeño de los indicadores técnicos y económicos. 


\section{Nota}

1 JANK, M. S.; GALAN, V. B. Competitividade do sistema agroindustrial do leite.

\section{Referências}

ABDI. Estudos Setoriais de Inovação: Projeto de Estudo sobre como as empresas brasileiras nos diferentes setores industriais acumulam conhecimento para realizar inovação tecnológica, Agência Brasileira de Desenvolvimento Industrial, 2005. p. 189.

AGUIAR, D. R. D. Leite Argentina, Brasil, Chile e Uruguai. In: BATALHA, M. O.; SOUZA FILHO, H. M. (Orgs.). O agronegócio no Mercosul: uma agenda para o desenvolvimento. São Paulo: Atlas, 2009.

ALMEIDA, M. B. de et al. Identificação e avaliação de aglomerações produtivas: uma proposta metodológica para o nordeste. Recife: IPSA/Pimes, 2003.

AQUIAF, Danilo R. A indústria de esmagamento de soja no Brasil: mudança estrutural, conduta e alguns indicadores de desempenho. Rev. Econ. Sociol. Rural, v. 32, n. 1, p. 23-46, 1994.

ASSOCIAÇÃO BRASILEIRA DOS PRODUTORES DE LEITE (LEITE BRASIL). Disponível em: <http://www.leitebrasil.org.br/maiores\%20laticinios.htm>. Acesso em: 11 dez. 2012.

BACHA, Carlos J. C. Economia e política agrícola no Brasil. São Paulo: Atlas, 2004.

BITENCOURT, D.; XAVIER, S. S.; BRIZOLA, R. M. O. Perspectiva e avanços em laticínios: Rio Grande do Sul "uma reflexão sobre a década de 90 e perspectivas do setor lácteo no ano de 2000". Juiz de Fora, MG, jun. 2000, p. 213-244.

BRUMER. S. Fundação de Economia e Estatística - FEE (2011). <http://www.fee.tche.br/sitefee/ download/teses/digitalizacao/teses_2.pdf>. Acesso em: 18 out. 2011.

CARVALHO, V. R. F. Indústria de laticínios no Rio Grande do Sul: um panorama após o movimento de fusões e aquisições. Disponível em: http://www.fee.tche.br/sitefee/download/eeg/1/ mesa_10_carvalho.pdf. Acesso em: 5 jan. 2012.

DUARTE, V. N. Caracterização dos principais segmentos da cadeia produtiva do leite em Santa Catarina. Disponível em <http://teses.eps.ufsc.br/defesa/pdf/4052.pdf>. Acesso em: 1 jun. 2005.

EMBRAPA Gado de Leite. Disponível em: <http://www.cnpgl.embrapa.br/nova/informacoes/estatisticas/producao/tabela0230.php>. Acesso em: $12 \mathrm{dez} .2012$.

EXAME. Disponível em: <http://exame.abril.com.br/negocios/empresas/noticias/fusao-cria-maior-empresa-de-laticinios-do-brasil>. Acesso em: 18 dez. 2012.

FEIJÓ, C. A.; CARVALHO, P. G. M.; RODRIGUEZ, M. S. Concentração industrial e produtividade do trabalho na indústria de transformação nos anos 90: evidências empíricas. Disponível em: $<$ http.www.anpec.org.br/revista/vol4/v4n1p19_52.pdf>. Acesso em: 7 jun. 2006.

MELO, F. H. Leite: a difícil formulação de uma política comercial. Revista de Economia e Sociologia Rural, v. 37, n. 4, 1999.

JANK, M. S.; GALAN, V. B. Competitividade do sistema agroindustrial do leite. Disponível em: http://www.fundace.org.br/leite/arquivos/projetos_priorizados/elaboracao_competitividade_industrial/bibliot/vol_ii_Leite\%20Competitividade_jank.pdf >. Acesso em: 5 jan. 2012.

KUPFER, D; HASENCLEVER, L. Economia Industrial: fundamentos teóricos e práticos no Brasil. Rio de Janeiro: Campus, 2002. 
MARION Filho, P. J. A evolução e a organização recente da indústria de móveis nos estados de Santa Catarina e Rio Grande do Sul. Piracicaba, 1997. 151p. Tese (Doutorado) - Escola Superior de Agricultura "Luiz de Queiroz", da Universidade de São Paulo.

MARION Filho, P. J.; LOPES, H. C. Mudança estrutural e competitividade: um estudo da alteração do padrão de concorrência do setor calçadista do Rio Grande do Sul. Disponível em: <http:// www.fee.tche.br/3eeg/Artigos/m17t01.pdf>. Acesso em: $11 \mathrm{dez} .2012$.

MARTINS, P. de C. Políticas públicas e mercados deprimem o resultado do Sistema Agroindustrial do Leite. Juiz de Fora: Embrapa Gado de Leite, 2004, 160p.

MARTINS, P. de C.; GOMES, E. T. Perspectivas e avanços em laticínios: mudança institucional: o grande desafio. Juiz de Fora, MG, Jun. 2000, Políticas públicas e mercados deprimem o resultado do Sistema Agroindustrial do Leite, p. 72-103.

MARTINS, L. M.; PADULA, A. D. Os relacionamentos privilegiados pela agroindústria láctea gaúcha no gerenciamento de sua cadeia de suprimentos. Porto Alegre. Dissertação (Mestrado) Escola de Adm. - UFRGS. 2000. Disponível em: < http://www.lume.ufrgs.br/handle/10183/3026>. Acesso em: 01 maio 2011.

MAZZETTO, T. S. C.; CAMARA, M. R. G.; DE PAULA, N. M. et al. Integração, desregulamentação, e estabilização: a expansão das transnacionais frente à mudança das condicionantes macroeconômicas no Brasil, no anos 90. Londrina, julho de 2007. Disponível em: < http://www.sober. org.br/palestra/6/1143.pdf>. Acesso em: 7 set. 2011.

MELO, J. L. de. (2002) Dinâmica concorrencial da indústria de laticínios no Brasil na década de 90: as cooperativas frente à abertura comercial. Tese (Doutorado) - UFV.

POCHMANN, M. A década dos mitos: o novo modelo econômico e a crise do trabalho no Brasil. São Paulo: Contexto, 2001.

PORTAL DA CIDADANIA. Normativa 51. Disponível em: <comunidades.mda.gov.br/o/776834>. Acesso em: 12 nov. 2012.

PORTER, M. E. Estratégia competitiva. Técnicas para analise de indústrias e concorrência. 2. Tiragem. Rio de Janeiro: Campus, 2004.

POSSAS, Mário L. Estrutura industrial brasileira: base produtiva e liderança dos mercados. Tese (mestrado). Campinas, Unicamp, 1977.

PRIMO, W. M. Perspectivas e avanços em laticínios: impactos da década de 90 para a indústria de laticínios. Juiz de Fora, MG, jun. 2000, p. 195-211.

SANTOS, M. A. S. dos; SANTANA, A. C. Estrutura de mercado e desempenho exportador das empresas de artefatos de madeira do estado do Pará, 2003. Disponível em: < http://www.basa. com.br/bancoamazonia2/includes/institucional/arquivos/biblioteca/artigos/economiaregional/EstruturadeMercado.pdf >. Acesso em: 5 jan. 2012.

SINDICATO DA INDÚSTRIA DE LATICÍNIOS E PRODUTOS DERIVADOS DO ESTADO DO RIO GRANDE DO SUL. Disponível em: <http://www.sindilat.com.br/gomanager/arquivos/ IN62_2011(2).pdf>. Acesso em: 15 dez. 2012.

TAVARES, M. C. et al. Estrutura industrial e empresas lideres. Relatório de pesquisa. Rio de Janeiro: Finep, 1978.

VIEIRA FILHO, J. E. R.; GASQUES, J. G.; SOUSA, A. G. de. Agricultura e crescimento: cenários e projeções. Brasília, texto para discussão, n. 1642, julho de 2011. Disponível em: <http://www. ipea.gov.br/portal/index.php?option=Comcontent\&view=icle\&id=1339\&Itemid=68\#>. Acesso em: 5 set. 2011.

ZYLBERSZTAJN, D.; NEVES, M. F. Economia e Gestão dos Negócios Agroalimentares. São Paulo: Pioneira, 2000. 